\title{
Removal of amoxicillin from wastewater by self-made Polyethersulfone membrane using nanofiltration
}

\author{
Ahmad Moarefian ${ }^{1 *}$, Hossein Alizadeh Golestani ${ }^{2}$ and Hooman Bahmanpour ${ }^{3}$
}

\begin{abstract}
The present study investigated the performance of a self-made nanofiltration (NF) membrane for the removal of antibiotics from wastewater under changing operating conditions such as $\mathrm{pH}$, initial feed concentration, operating pressure, and temperature. Amoxicillin (AMX) was used as one of the commonly prescribed antibiotics. A self-made NF membrane containing Polyethersulfone (PES), and Polyvinylpyrrolidone (PVP) was modified with Polyethylene glycol hexadecyl ether (Brijø58) surfactant. The self-made membrane was characterized by water contact angle, zeta potential, ATR-FTIR spectroscopy, and scanning electronic microscope (SEM). The obtained results showed that the AMX rejection and permeation flux by the self-made membrane varied from $56.49 \%$ to $99.09 \%$ and from $15.14 \mathrm{~L} / \mathrm{m}^{2} \mathrm{~h}$ to $110.29 \mathrm{~L} / \mathrm{m}^{2} \mathrm{~h}$, respectively. The AMX rejection decreased at a higher level of initial feed concentration while other operating parameters such as $\mathrm{pH}$, operating pressure, and temperature had a negligible effect on the removal of AMX from wastewater by the self-made NF membrane. The highest removal rate was achieved under conditions of pH 9.0, a temperature of $298 \mathrm{~K}$, an operating pressure of $2 \mathrm{MPa}$, and an initial feed concentration of $20 \mathrm{ppm}$. According to the research findings, the self-made NF membrane is recommended for the removal of AMX to a considerable extent at low initial feed concentrations.
\end{abstract}

Keywords: Nanofiltration, Polyethersulfone membrane, Amoxicillin removal, Wastewater treatment

\section{Introduction}

The occurrence of antibiotics as emerging containment substances in aquatic environments has always been a cause of concern due to the destructive potential on ecosystems. Prolonged exposure to trace levels of antibiotics leads to the selective proliferation of antibiotic-resistant bacteria and long-term adverse effects on ecosystems and human health [1-7]. However, antibiotic residues have been detected in surface water, ground water, and the final effluent of wastewater treatment plants (WWTPs), even at low concentrations in the range of nanograms/ micrograms per liter [8-10].

Although Amoxicillin (AMX) is used to treat a number of infections, however, it is suspected of direct toxic effects on certain aquatic organisms [11-15]. Moreover, amoxicillinresistant pathogens, such as Klebsiella pneumoniae, and

\footnotetext{
*Correspondence: a_moarefian@yahoo.com

'Department of Chemical Engineering, College of Science, Shahrood Branch, Islamic Azad University, Shahrood, Iran

Full list of author information is available at the end of the article
}

Bacteroides spp [16] in aquatic environments are a potential health threat and make water aesthetically pleasing. According to above-mentioned details, antibiotic residues such as AMX should be removed from aqueous matrices. Common physical and chemical treatment methods are not suitable for the removal of large quantities $(\mathrm{mg} / \mathrm{L})$ of pharmaceutically active compounds (PhACs) from wastewater $[17,18]$. Accordingly, these methods are not efficient for treatment of PhACs [19].

Efficient removal of the polar PhACs can only be ensured using more advanced methods such as ozonation, advanced oxidation processes (AOP), activated carbon, or membrane filtration [19]. However, high cost of equipment and maintenance, as well as energy supply are of disadvantages of the ozonation technique [6]. Capital intensive required to quenching of excess peroxide for some applications [20] rejects the use of AOP. Although granular activated carbons (GACs) are applicable adsorbents, however, they are costly and their regeneration is difficult [6]. The removal efficiency by activated carbon is low for PhACs having low log 
$\mathrm{K}_{\mathrm{ow}}$ values (e.g. AMX by $\log \mathrm{K}_{\mathrm{ow}}=0.87$ [21]) and low electrical charges [19].

Membrane technologies such as nanofiltration (NF) and reverse osmosis (RO) have extensively been used for municipal wastewater treatment purposes to ensure the quality of municipal effluents and wastewater reuse [18]. Pressure-driven membrane processes, particularly NF and $\mathrm{RO}$ have been the centre of attention in the past few years especially for treatment of drinking water $[22,23]$.

$\mathrm{NF}$ is a relatively recent membrane filtration process being used up rapidly [24]. NF membranes are mainly used for the removal of dissolved PhACs from water matrices $[22,25]$. Compliance of molecular mass (MW) of PhACs ranges between 200 and $1200 \mathrm{Da}$, with the molecular mass cutoff (MWCO) of NF membranes [24], NF seems to be an efficient technique for the removal of antibiotics from contaminated water [26].

Most NF membranes are charged by the dissociation of surface functional groups such as carboxylic or sulfonic $[6,25]$. Negatively charged NF membranes are widely used because they can selectively pass or reject the ions from feed solution through the electrostatic interaction between ions and membrane surface $[6,25]$.

Moreover, different rejection mechanisms have been proposed to NF process, which include, molecular sieving (steric hindrance), Donnan exclusion (electrostatic interaction between charged solutes and membrane-attached charges), and dielectric exclusion (interaction between ions and the polarized charge) [25]. In spite of many methods on characterization of NF membranes, the transport mechanisms of solutes through membranes are not completely understood [25].

This research was conducted to investigate the performance of a self-made membrane for removal of AMX from synthetic wastewater under varying operating conditions.

\section{Materials and methods Materials}

Polyethersulfone $(\mathrm{Mw}=58000 \mathrm{~g} / \mathrm{mol})$ provided by BASF Co. was used to prepare membrane casting solution. Pure AMX $(\mathrm{Mw}=365.40 \mathrm{~g} / \mathrm{mol})$ was prepared from Dana Pharmacy Co. (Tabriz, Iran). Polyvinylpyrrolidone $(\mathrm{Mw}=40000 \mathrm{~g} / \mathrm{mol})$, 1-Methyl-2-pyrrolidinone (NMP) as a polymer solvent, and Polyethylene glycol hexadecyl ether (Brij 58 ) as a non-ionic surfactant $(\mathrm{HLB}=15.7)$ were purchased from Sigma Aldrich Co. (USA). N,N-dimethyl-p-phenylenediamine, potassium hexacyanoferrate (iii), $\mathrm{NH}_{3}$, and $\mathrm{NaOH}$ were bought from Merck Co. (Germany) to determine AMX content in feed and permeate flow. Molecular structure of PES, Brij 58 , PVP, NMP, and AMX is shown in Figure 1.

\section{Membrane preparation}

The self-made membrane was prepared by phase inversion method using optimal amounts of PES, PVP, and Brij 58 surfactant. The Brij 58 was used as a non-ionic surfactant to modify the PES membrane. The casting solution was prepared by dissolving $1.143 \mathrm{~g}$ of Brij 58 in $13.155 \mathrm{~mL}$ of NMP, then $4.000 \mathrm{~g}$ of PES and $0.381 \mathrm{~g}$ of PVP was gently added to residue materials as a pore former and stirred overnight at $300 \mathrm{rpm}$. After preparing a homogeneous solution, the dope was kept at room temperature for about $24 \mathrm{~h}$ until the air bubbles were removed. The homogenous solution was casted onto a glass substrate hovering at a height of $200 \mu \mathrm{m}$ using a film applicator at room temperature without evaporation. Then, the solution was transferred to a deionized water bath for immersion precipitation at $273 \mathrm{~K}$ and allowed it to stand for 5 minutes.

The prepared membrane was stored in distilled water for $24 \mathrm{~h}$ to allow the water soluble components to be leached out. Finally, the membrane was dried by two filter papers under very low uniform pressure.

\section{Synthetic wastewater}

The synthetic wastewater with initial feed concentrations of 20 and $400 \mathrm{ppm}$ was prepared by dissolving 0.2 and $4 \mathrm{~g}$ of AMX in $10 \mathrm{~L}$ distilled water. In order to investigate the effect of $\mathrm{pH}$ on the performance of the self-made membrane for the removal of AMX, all the experiments were conducted at $\mathrm{pH}$ values of $5,7.0$, and 9.0. The $\mathrm{pH}$ of feed solution was about 5. 0.1 $\mathrm{M}(0.1 \mathrm{~N})$ sodium hydroxide $(\mathrm{NaOH})$ was added to the synthetic wastewater in order to adjust the $\mathrm{pH}$ at 7.0 and 9.0.

\section{Membrane characterization Contact angle}

In order to evaluate membrane hydrophilicity, static contact angle between water and the membrane was measured directly using an OCA 15 Plus (Data Physics Instruments, Germany). Deionized water was used as a probe liquid in all measurements. All contact angle measurements were made using deionized water drops of $4 \mu \mathrm{l}$. To minimize experimental errors, for each sample, the contact angle was measured at 4 random locations and then, the average value was considered.

\section{Zeta potential}

To determine electrical charge over the membrane surface, zeta potential was determined by streaming potential measurements using Electro Kinetic Analyzer (EKA 1.00, Anton-Paar, Swiss) equipped with a plated sample cell. Zeta potential was measured in a $0.001 \mathrm{M} \mathrm{KCl}$ solution. The measurements were carried out at $298 \mathrm{~K}$ in $\mathrm{KCl}$ solution $(0.001 \mathrm{M})$ with polymethyl methacrylate (PMMA) plate. Zeta potential was measured at $\mathrm{pH}$ values of 5.0, 7.0, and 9.0.

\section{Morphologic study}

The morphology of the self-made membrane was studied by an electronic microscope (EM 3200, KYKY, China). For 


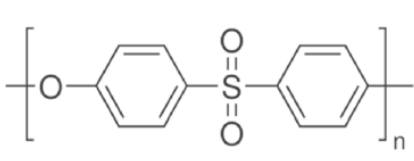

Polyethersulfone

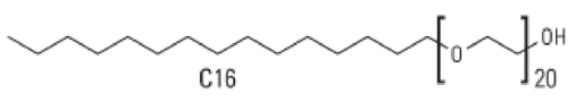

Polyethylene glycol hexadecyl ether

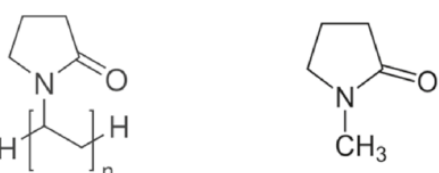

1-Methyl-2-pyrrolydinone

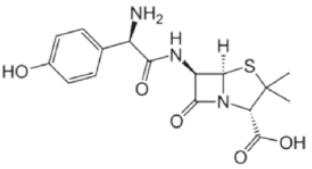

Amoxicillin

Figure 1 Chemical structure of PES, PVP 40, NMP, Brij ${ }^{\circledR} 5$ and AMX.

this, a sample of the membrane was frozen in liquid nitrogen and then fractured. After gold sputtering, it was examined by an electron microscopy at $20 \mathrm{kV}$.

\section{ATR-FTIR spectroscopy}

In order to ensure the presence of Brij 58 surfactant in the structure of synthetic membrane, the ATR-FTIR spectroscopy was used. The Fourier transform infrared (FTIR) spectrum of the membrane was recorded in the range between 400 and $4000 \mathrm{~cm}^{-1}$ using attenuated total reflection (ATR) technique by Nicolet IR 100 FTIR spectrometer (Thermo, USA).

\section{Experimental set-up}

NF experiments were conducted in a consecutive lab-scale filtration equipped with a cross-flow permeation cell with an effective filtration area of $6.936 \times 10^{-3} \mathrm{~m}^{2}$ supported by a porous stainless steel disc. Details of the permeation cell and NF set-up are depicted in Figure 2. The temperature of feed solution was maintained at 298,308 , and $318 \mathrm{~K}$ by a shell and tube heat exchanger. The operating pressure can be varied from 0.5 to $2 \mathrm{MPa}$. Pressure was adjusted by backpressure and bypass valves. Retentate and permeate streams were directed back into the feed tank in a closed cycle, which makes the feed concentration approximately constant.

\section{Membrane performance}

The membrane was cut into appropriate size required to fix up the NF membrane cell and then pressurized with distilled water at $2 \mathrm{MPa}$ for $1 \mathrm{~h}$. After compression, the pressure was dropped to the operating pressure level of $0.5,1$, and 1.5 MPa. Subsequently, the pure water flux (PWF) was collected for $1 \mathrm{~h}$ and calculated using the Eq. (1).

$$
\mathrm{PWF}=\mathrm{Q} / \mathrm{A} \Delta \mathrm{t}
$$

Where; PWF = pure water flux $\left(\mathrm{L} / \mathrm{m}^{2} \mathrm{~h}\right), \mathrm{Q}=$ quantity of permeate $(\mathrm{L}), \mathrm{A}=$ active membrane area $\left(\mathrm{m}^{2}\right)$, and $\Delta \mathrm{t}=$ sampling time (h).

After filtration of the pure water, the feed tank was emptied and refilled with the synthetic wastewater. The

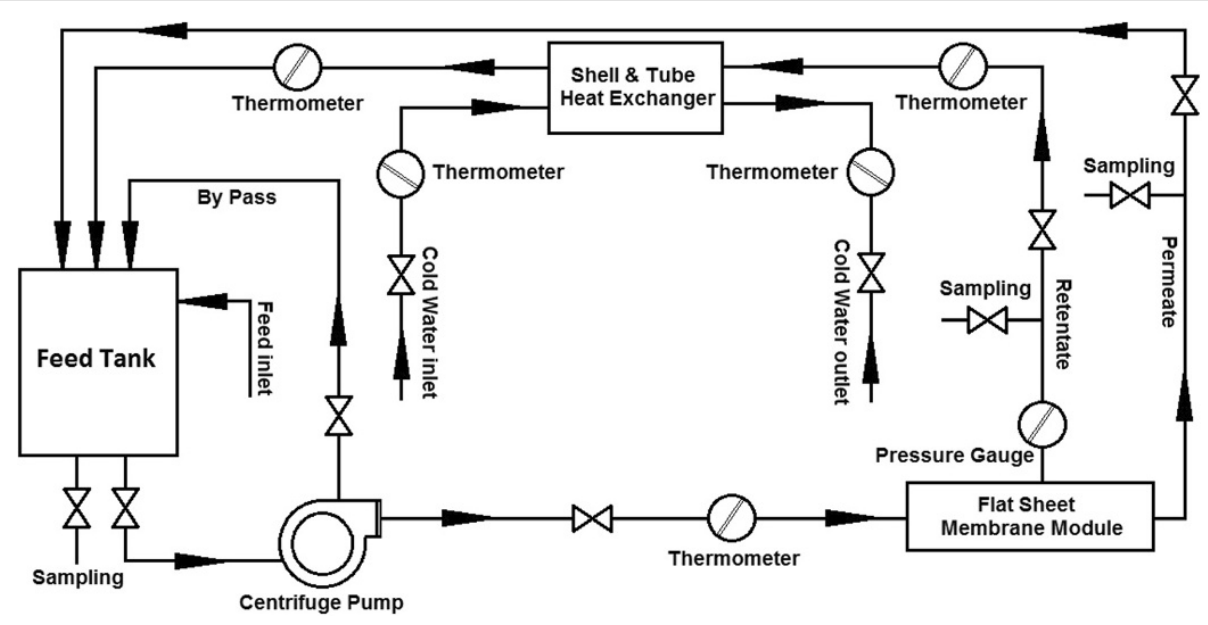

Figure 2 Schematic diagram of the NF set-up. 
membrane performance was studied in terms of either permeation flux or AMX rejection. The solute rejection was calculated using Eq. (2).

$$
R(\%)=\left[\left(1-C_{P} / C_{F}\right)\right] \times 100
$$

Where; $C_{P}$ and $C_{F}$ are concentrations of the solute in permeate and initial feed solutions, respectively. Concentration of AMX in the permeate stream was
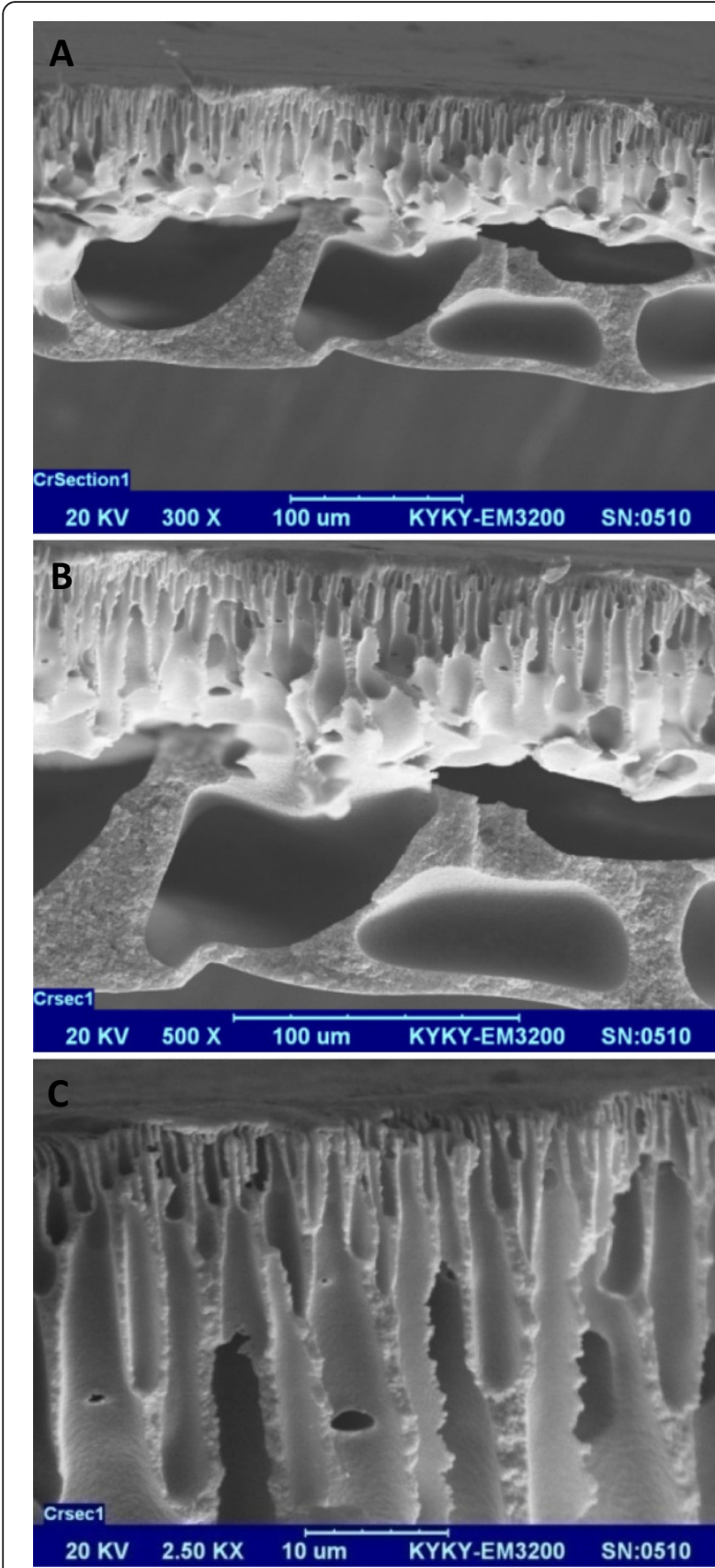

Figure 3 SEM cross-section of the self-made membrane at magnifications of A) $300 \times$, B) $500 x$, and C) $2500 x$. determined using N,N-dimethyl-p-phenylenediamine, potassium hexacyanoferrate (iii), and $\mathrm{NH}_{4} \mathrm{OH}$. The absorbance of samples was measured by T60 UV-Vis spectrophotometer (PG Instruments, England) at the maximum wavelength. The measurement technique relies on the Beer-Lambert Law [27].

\section{Results and discussion}

\section{Membrane morphology}

Separation of neutral solutes by porous membranes is mainly a function of molecular and pore size distribution [28]. Accordingly, membranes with a higher pore density, surface porosity, and porous sub-layer have a higher permeation flux [29]. In other word, higher porosity provides more pore channels for diffusion that leads to a higher flux. However, the morphologic study can help to predict rejection rate of neutral solutes as well as permeation rate of flux. The SEM images of the self-made membrane demonstrate an asymmetric structure consisting of a dense top-layer and a porous sub-layer (Figure 3). The morphology of the asymmetric synthetic membrane demonstrated finger-like macrovoids developed underneath the dense layer. Higher rate of permeation flux and AMX rejection is expected due to the high-porous sub-layer of the self-made membrane (each pore size ranges between 0.5 and $5 \mu \mathrm{m}$ ) and a dense selective top-layer consisting of nanopores.

\section{Pure water flux}

Figure 4 shows that the PWF tends to increase with increasing TMP. According to which, increased pressure is an effective way to increase permeation flux. Furthermore, there is a linear relation $\left(R^{2}=0.994\right)$ between PWF and TMP. As regards, NF is a pressure-driven procedure, transmembrane pressure (TMP) is a very crucial factor in the separation performance. Furthermore, as a constant-pressure procedure, TMP determines membrane

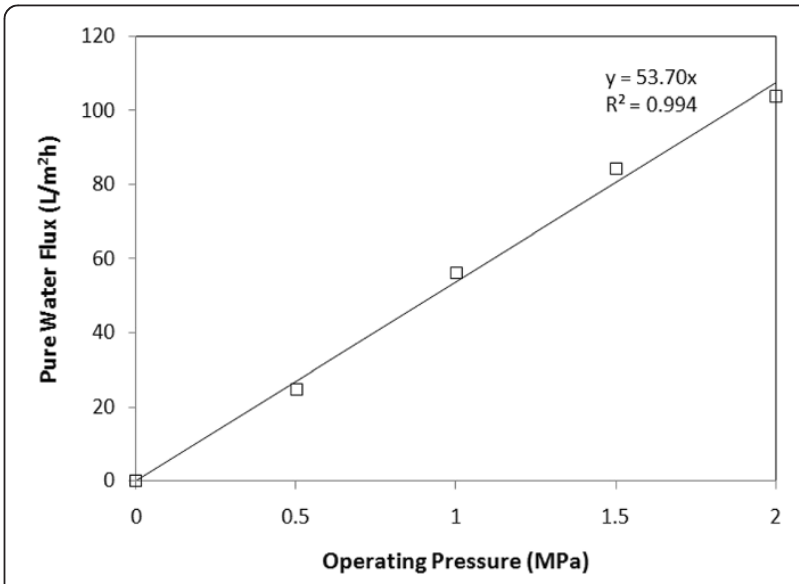

Figure 4 PWF vs. operating pressure at $\mathrm{T}=298 \mathrm{~K}$ for PES/PVP/ Brij 58 Membrane. 


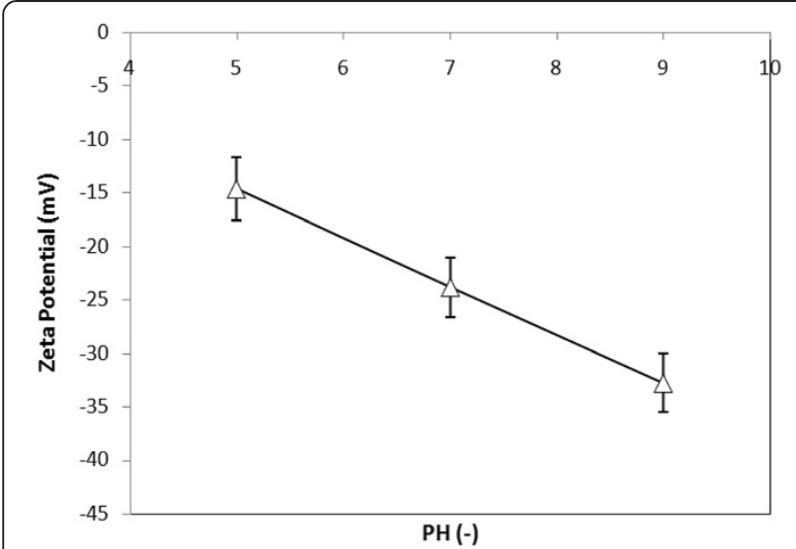

Figure 5 Zeta potential of the self-made NF membrane as function of $\mathrm{pH}$ values.

permeability [30]. Accordingly the permeate flux is proportional to the TMP.

\section{Contact angle measurements}

As the obtained results show, the highest water contact angle belongs to the unmodified PES membrane, which indicates the lowest hydrophilicity. A low contact angle with water indicates that the surface is hydrophilic. According the obtained result, the water contact angle on the PES membrane decreased from $74.7^{\circ}$ to $28.3^{\circ}$ once an optimal amount of Brij 58 surfactant was added to the casting solution. This may be attributed to the Brij 58 surfactant and morphology of the top and bottom surfaces of the membrane. As mentioned earlier, the PES membrane was modified by adding an optimal of Brij 58 to the casting solution. Therefore, changes in contact angle may relate to membrane modification. According to literature $[31,32]$, the contact angle values depend on chemistry, roughness, and heterogeneity of surface as well as membrane parameters. This is consistence with the findings of the current study.

\section{Membrane surface charge}

Zeta potential values presented in Figure 5 reveal negative charge of the NF membrane surface as well as a decrease in the absolute value of zeta potential at acidic $\mathrm{pH}$. Zeta potential refers to surface charge that occurs in the presence of an aqueous solution when functional groups dissociate on surface or ions adsorb onto surface from the solution $[33,34]$. Since PES has no dissociated functional groups [35], specific ionic adsorption is the only possible process for the formation of surface charge.

\section{ATR-FTIR spectroscopy}

ATR-FTIR spectroscopy was used to ensure the presence of Brij 58 surfactant in the structure of the synthetic membrane during preparation process, especially in the coagulation stage. Figure 6 exhibits the surface ATR-FTIR spectra of the synthetic membrane. The functionalized self-made membrane illustrates four main peaks. The PES contains repeated ether and sulfone linkage alternating between aromatic rings. Accordingly, the bands at 1151 and $1241 \mathrm{~cm}^{-1}$ can be attributed to the stretching vibrations of $\mathrm{S}=\mathrm{O}$ symmetric and $\mathrm{S}=\mathrm{O}$ asymmetric, respectively. Besides, the bands at 1663, 3300-3600 and $2919 \mathrm{~cm}^{-1}$ depict the amide group of PVP, $(-\mathrm{OH})$, and $\mathrm{C}-\mathrm{H}$ groups of Brij 58 surfactant, respectively. However, the spectrum of PES/PVP/Brij 58 membrane shows that Brij 58 surfactant was retained in the membrane structure.

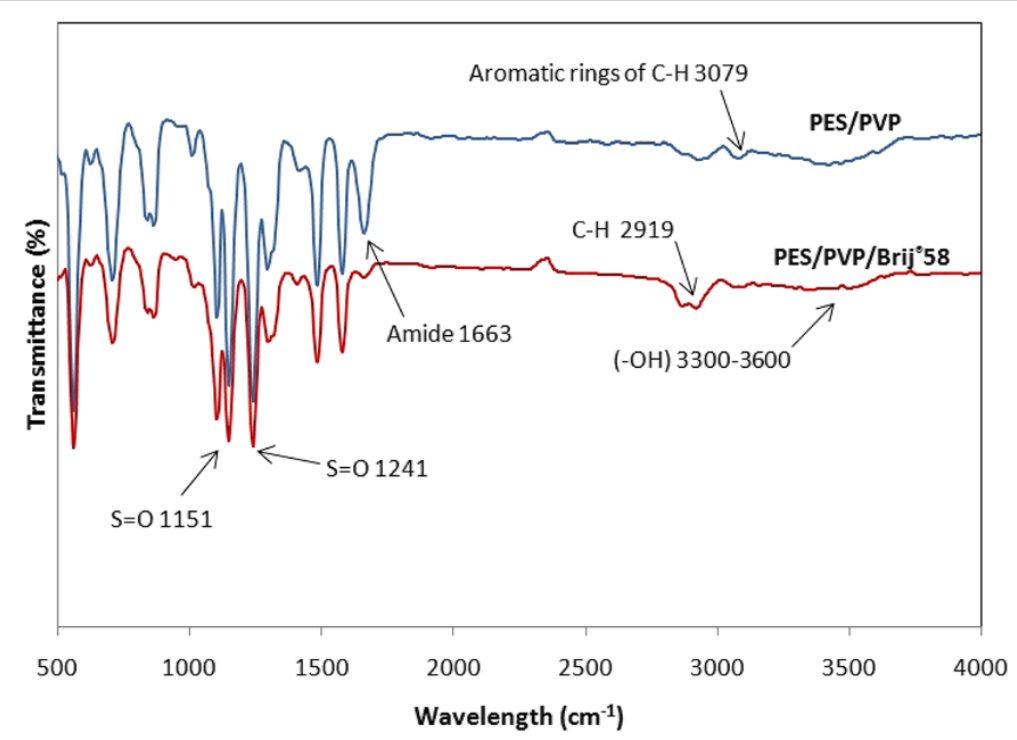

Figure 6 ATR-FTIR spectra of the PES/PVP and PES/PVP/Brij ${ }^{\oplus 5} 5$ membranes. 
Antibiotic rejection and permeation flux

The performance of the self-made membrane for the removal of AMX from wastewater is depicted in Figures 7 and 8. As the figures show, rejection and permeation flux by the self-made membrane varied from $56.49 \%$ to 99.09\% and from $15.14 \mathrm{~L} / \mathrm{m}^{2} \mathrm{~h}$ to $110.29 \mathrm{~L} / \mathrm{m}^{2} \mathrm{~h}$, respectively. As shown by Figure 7, the effect of initial feed concentration on AMX rejection was much more than that of
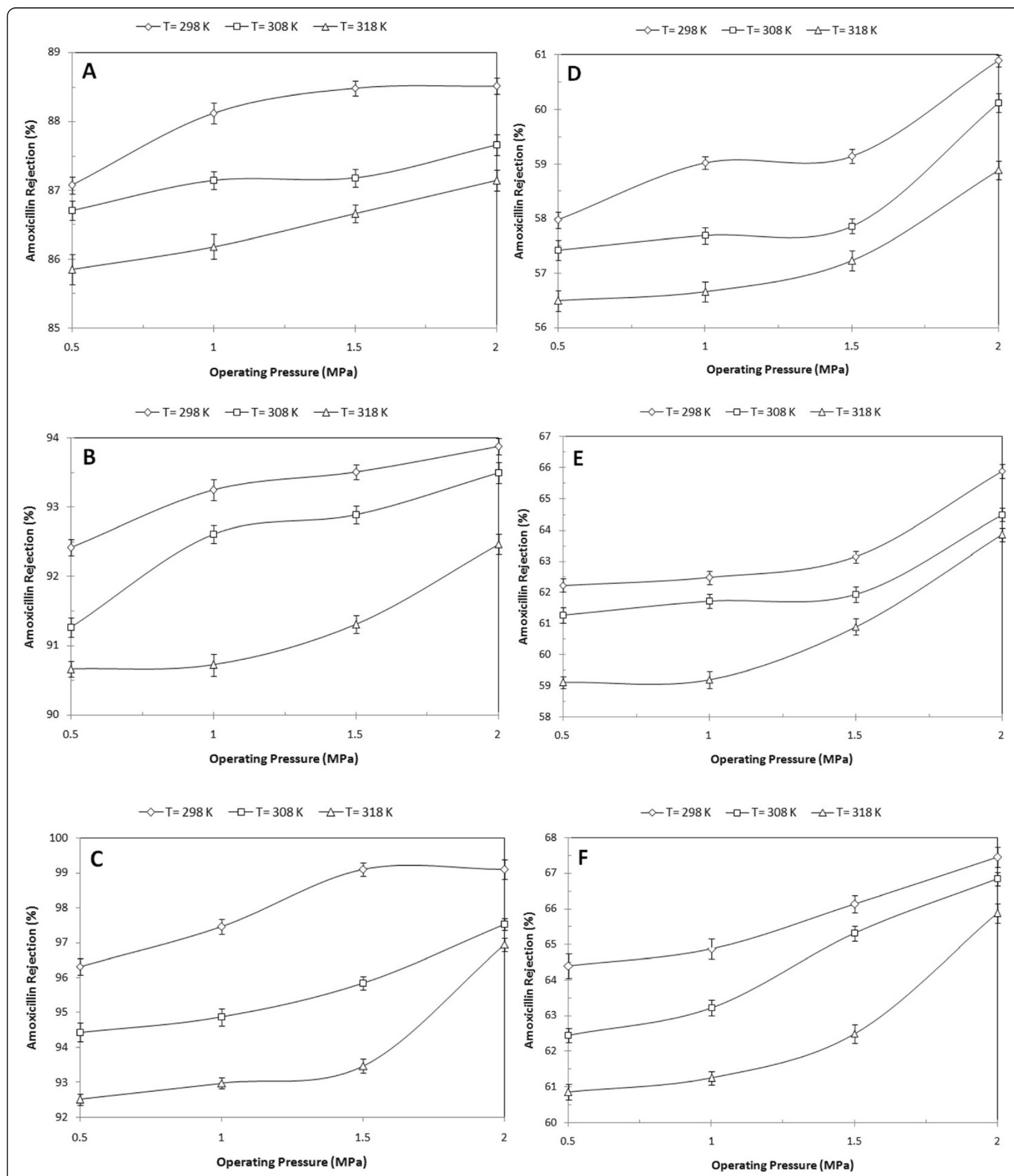

Figure 7 Rejection of AMX vs. operating pressure at varying temperature and initial feed concentration. A) $20 \mathrm{ppm} / \mathrm{pH}=5.27$,

B) $20 \mathrm{ppm} / \mathrm{pH}=7.0$, C) $20 \mathrm{ppm} / \mathrm{pH}=9.0$, D) $400 \mathrm{ppm} / \mathrm{pH}=5.01$, E) $400 \mathrm{ppm} / \mathrm{pH}=7.0$, F) $400 \mathrm{ppm} / \mathrm{pH}=9.0$. 

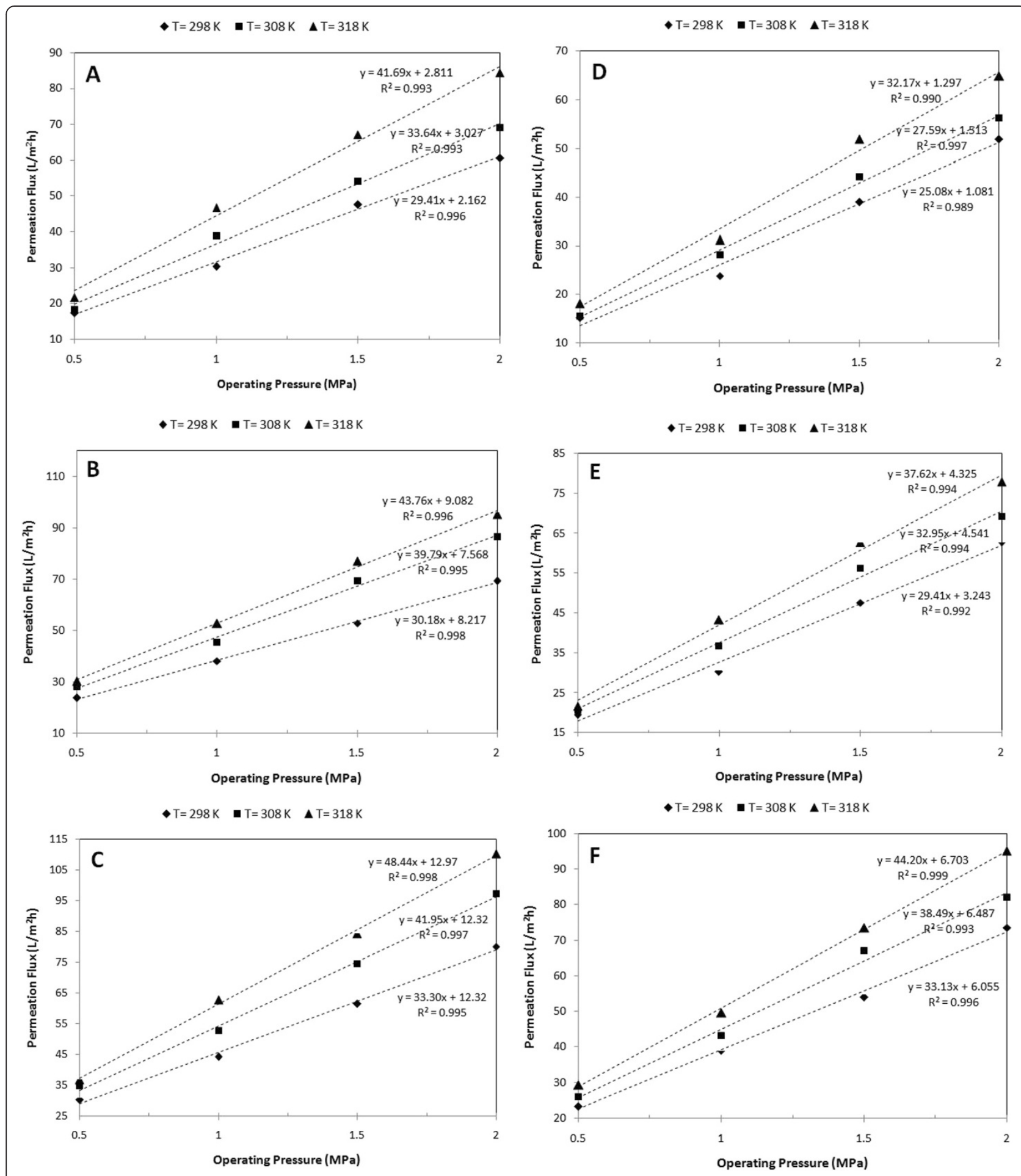

Figure 8 Permeation Flux vs. operating pressure at varying temperature and initial feed concentration. A) $20 \mathrm{ppm} / \mathrm{pH}=5.27$,

B) $20 \mathrm{ppm} / \mathrm{pH}=7.0$, C) $20 \mathrm{ppm} / \mathrm{pH}=9.0$, D) $400 \mathrm{ppm} / \mathrm{pH}=5.01$, E) $400 \mathrm{ppm} / \mathrm{pH}=7.0$, F) $400 \mathrm{ppm} / \mathrm{pH}=9.0$.

$\mathrm{pH}$. Furthermore, the effect of operating pressure and temperature on the AMX rejection was noticeable.

According to Figure 8, the operating pressure, $\mathrm{pH}$, and temperature have remarkable effects on the permeation flux.
The Pearson Correlation test results on AMX rejection and permeation flux are shown in Table 1. According to the results, the feed concentration has a significant effect on AMX rejection $(\mathrm{P}<0.001)$ while it has no significant 
Table 1 Pearson Correlation test for AMX rejection and permeation flux

\begin{tabular}{|c|c|c|c|c|c|c|c|}
\hline \multicolumn{8}{|l|}{ Correlations } \\
\hline & & $\mathrm{pH}$ & Concentration & Pressure & Temperature & Rejection & Permeation flux \\
\hline \multirow[t]{4}{*}{$\mathrm{pH}$} & Pearson Correlation & 1 & & & & & \\
\hline & Sig. (2-tailed) & & & & & & \\
\hline & R Square & & & & & & \\
\hline & $\mathrm{N}$ & 72 & & & & & \\
\hline \multirow[t]{4}{*}{ Concentration } & Pearson Correlation & .000 & 1 & & & & \\
\hline & Sig. (2-tailed) & 1.000 & & & & & \\
\hline & R Square & & & & & & \\
\hline & $\mathrm{N}$ & 72 & 72 & & & & \\
\hline \multirow[t]{4}{*}{ Pressure } & Pearson Correlation & .000 & .000 & 1 & & & \\
\hline & Sig. (2-tailed) & 1.000 & 1.000 & & & & \\
\hline & R Square & & & & & & \\
\hline & $\mathrm{N}$ & 72 & 72 & 72 & & & \\
\hline \multirow[t]{4}{*}{ Temperature } & Pearson Correlation & .000 & .000 & .000 & 1 & & \\
\hline & Sig. (2-tailed) & 1.000 & 1.000 & 1.000 & & & \\
\hline & R Square & & & & & & \\
\hline & $\mathrm{N}$ & 72 & 72 & 72 & 72 & & \\
\hline \multirow[t]{4}{*}{ Rejection } & Pearson Correlation & .192 & $-.975^{* *}$ & .067 & -.067 & 1 & \\
\hline & Sig. (2-tailed) & .105 & .000 & .575 & .576 & & \\
\hline & R Square & .037 & .950 & .005 & .004 & & \\
\hline & $\mathrm{N}$ & 72 & 72 & 72 & 72 & 72 & \\
\hline \multirow[t]{4}{*}{ Permeation flux } & Pearson Correlation & $.318^{* *}$ & -.211 & $.868^{* *}$ & $.261^{*}$ & $.308^{* *}$ & 1 \\
\hline & Sig. (2-tailed) & .007 & .076 & .000 & .027 & .008 & \\
\hline & R Square & .101 & .044 & .754 & .068 & & \\
\hline & $\mathrm{N}$ & 72 & 72 & 72 & 72 & 72 & 72 \\
\hline
\end{tabular}

${ }^{* *}$ Correlation is significant at the 0.01 level (2-tailed).

*Correlation is significant at the 0.05 level (2-tailed).

effect on the permeation flux. As such, AMX rejection decreased at high initial feed concentration of $400 \mathrm{ppm}$ (Figure 7). This may be due to increased corresponding ionic strength that tends to neutralize the negative charges of the membrane and consequently, decrease electrostatic repulsion. Finally, a large number of ions pass through the membrane pores that result in a reduction in AMX rejection.

Although, based on Figure 7 , rejection rate of the AMX changed by $\mathrm{pH}$ changes, however, the impact of these changes is not noticeable according to Table 1 . The results showed that increasing the $\mathrm{pH}$ from 5 to 9.0 increased rejection efficiency of AMX by $7 \%$. AMX is an amphoteric substance with $\mathrm{pKa}_{1}=2.4, \mathrm{pKa}_{2}=7.4$, and $\mathrm{pka}_{3}=9.6$ [36]. AMX is zwitterions at medium pHs, a cation at $\mathrm{pH}=2$, and an anion at $\mathrm{pHs}$ above 7.4. Therefore, at higher pHs, AMX converts anionic forms. Surface charge of the self-made membrane becomes more negative with increasing $\mathrm{pH}$ (Figure 5). At a lower $\mathrm{pH}$ (5.27), molecular sieve mechanism dominates and results in medium rejection while at higher $\mathrm{pH}$ (9.0), Donnan repulsion mechanism involving electrostatic charge interactions between solute and membrane surface occurs. This leads to electrostatic repulsion between the AMX and self-membrane and higher membrane permeability $(\mathrm{P}<0.001)$.

Significant effect of $\mathrm{pH}$ on permeability and AMX rejection by NF membrane has been confirmed by many researchers worldwide. As such, Derakhsheshpoor et al. investigated the effect of $\mathrm{pH}$ on the AMX rejection by high permeability polysulfone NF membrane. They observed that increasing feed $\mathrm{pH}$ from 6.3 to 8.3 , improved $30 \%$ of AMX recovery [36].

Since NF is a pressure-driven process, increased pressure leads to an increase in permeate flux. According to Figure 8 , the permeation flux increases with increasing operating pressure. This is due to the solution-diffusion model. According to Table 1, operating pressure has a significant effect on permeation flux $(\mathrm{P}<0.01)$.

As Figure 7 suggests, increasing operating pressure from 0.5 to $2 \mathrm{MPa}$ leads to an increase of approximately 
3\% in the AMX rejection. In other words, at high pressure, water permeability increases rapidly compared to the AMX by which greater number of water molecules can pass through the membrane. Based on Pearson Correlation test results (Table 1), the effect of operating pressure on AMX rejection is negligible.

Increased temperature leads to decreased AMX rejection (Figure 7) and increased permeation flux (Figure 8). This is due to the fact that increased temperature expedites thermal motion of molecules within the membrane, which contributes to the increase in the diffusion coefficient. Thus, transport of components is mainly controlled by the diffusion process in the membrane. In addition, the average pore size of the active separation layer increases slightly when the operating temperature goes up. It is in favor of an increase in permeation flux $(\mathrm{P}<0.05)$.

Considering to Table 1, temperature change has no significant effect on the diffusion coefficient and rejection of AMX because the huge molar volume of AMX blocks the movement of AMX in the membrane.

\section{Conclusion}

In this study, the self-made membrane was modified by a non-ionic surfactant (Brij 58 ). The self-made membrane was characterized by measuring zeta potential and contact angle. Modification of the membrane by Brij 58 surfactant was detected through ATR-FTIR spectroscopy. Moreover, the effect of operating conditions such as $\mathrm{pH}$, feed concentration, operating pressure, and temperature on performance of the self-made membrane for removal of AMX from synthetic wastewater.

The results showed that adding an optimal amount of Brij 58 into the casting solution leads to a decrease in water contact angle. In other words, low water contact angle indicates that the membrane is hydrophilic. As the obtained results revealed, a increase in $\mathrm{pH}$ from 5 to 9.0 increases the permeation flux of approximately $18 \mathrm{~L} / \mathrm{m}^{2} \mathrm{~h}$ on average. Besides, an increase in pressure and temperature leads to increased permeation flux of the self-made membrane. The analysis results of the Pearson Correlation (Table 1) confirm that $\mathrm{pH}(\mathrm{P}<0.01)$, operating pressure $(\mathrm{P}<0.01)$, and temperature $(\mathrm{P}<0.05)$ have a significant effect on permeation flux, while operating pressure is not an effective parameter to improve the rejection efficiency. According to which, an increase in the operating pressure from 0.5 to $2 \mathrm{MPa}$ increased the AMX rejection by approximately $3 \%$. Moreover, $\mathrm{pH}$ and temperature have no significant effect on AMX rejection by the self-made membrane, as well.

Increased concentration adversely affects the efficiency of AMX rejection. In overall, maximum AMX rejection of 99.09\% was achieved at operating temperature of $298 \mathrm{~K}$, operating pressure of $2 \mathrm{MPa}$, initial feed concentration of $20 \mathrm{ppm}$, and $\mathrm{pH}$ of 9.0 .
However, retention of organic pollutants in membrane separation process depends on the operating condition and characteristics of both membrane and pollutants. Generally, feed concentration is the only parameter affects adversely the rejection of AMX by self-made membrane. Considering AMX rejection efficiency of $99.09 \%$ by the self-made membrane at the initial feed concentration of $20 \mathrm{ppm}$, it can be concluded that this modified membrane is well suited for the removal of AMX from aquatic matrices containing low concentrations of this kind of pollutant. Other operating parameters such as temperature and pressure as well as the qualitative parameters of wastewater such as $\mathrm{pH}$ have negligible effect on AMX rejection by the self-made membrane. As a result, the self-made membrane is highly recommended under the above mention conditions.

\section{Competing interests}

The authors declare that they have no competing interest.

\section{Authors' contributions}

AM participated in data gathering and design of the study. He also coordinated research activities, and revised the manuscript. HAG carried out technical analysis of data, participated in design of the study, and drafted the manuscript. $\mathrm{HB}$ participated in the design of the study, final revision of the manuscript, and data analysis. All authors read and approved the finalized manuscript.

\section{Acknowledgements}

The authors wish to thank for technical assistance provided by Maryam Omidvar and Dana Pharmacy Company for amoxicillin supply.

\section{Author details}

'Department of Chemical Engineering, College of Science, Shahrood Branch, Islamic Azad University, Shahrood, Iran. '2Department of Chemical Engineering, Quchan Branch, Islamic Azad University, Quchan, Iran. ${ }^{3}$ Department of Environment, College of Science, Shahrood Branch, Islamic Azad University, Shahrood, Iran.

\section{Received: 3 May 2014 Accepted: 14 October 2014}

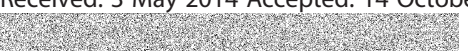

\section{References}

1. Batt $A L$, Bruce IB, Aga DS: Evaluating the vulnerability of surface waters to antibiotic contamination from varying wastewater treatment plant discharges. Environ Pollut 2006, 142:295-302.

2. Huang JJ, Hu HY, Lu SQ, Li Y, Tang F, Lu Y, Wei B: Monitoring and evaluation of antibiotic-resistant bacteria at a municipal wastewater treatment plant in China. Environ Int 2012, 42:31-36.

3. Zhang Y, Marrs CF, Simon C, Xi C: Wastewater treatment contributes to selective increase of antibiotic resistance among Acinetobacter spp. Sci Total Environ 2009, 407:3702-3706.

4. Tennstedt T, Szczepanowski R, Braun S, Puhler A, Schluter A: Occurrence of integron-associated resistance gene cassettes located on antibiotic resistance plasmids isolated from a wastewater treatment plant. FEMS Microbiol Ecol 2003, 45:239-252.

5. Rizzo L, Manaia C, Merlin C, Schwartz T, Dagot C, Ploy MC, Michael I, Fatta-Kassinos D: Urban wastewater treatment plants as hotspots for antibiotic resistant bacteria and genes spread into the environment: a review. Sci Total Environ 2013, 447:345-360.

6. Homem V, Santos L: Degradation and removal methods of antibiotics from aqueous matrices-a review. J Environ Manage 2011, 92:2304-2347.

7. Watkinson AJ, Murby EJ, Kolpin DW, Costanzo SD: The occurrence of antibiotics in an urban watershed: from wastewater to drinking water. Sci Total Environ 2009, 407:2711-2723.

8. Carrithers S, Sessoms H, Crone T: Pharmeceutical Screening of Surface Water, Ground Water, and Stream Bed Sediment in Gallatin Valley, Montana. Montana: Water Quality Research Associates; 2007:1-31. 
9. Brown KD: Pharmaceutically Active Compounds in Residential and Hospital Effluent, Municipal Wastewater, and the Rio Grande in Albuquerque, New Mexico. Albuquerque, New Mexico: Water Resources Program, The University of New Mexico; 2004:1-56.

10. Verlicchi $P, A$ A Aukidy M, Zambello E: Occurrence of pharmaceutical compounds in urban wastewater: removal, mass load and environmental risk after a secondary treatment-a review. Sci Total Environ 2012, 429:123-155.

11. Pan X, Deng C, Zhang D, Wang J, Mu G, Chen Y: Toxic effects of amoxicillin on the photosystem II of Synechocystis sp. characterized by a variety of in vivo chlorophyll fluorescence tests. Aquat Toxicol 2008, 89:207-213.

12. Sun J, Li W, Zheng P, Zhu J: Toxicity evaluation of antibiotics in piggery wastewater by luminescent bacteria. Pol J Environ 2012, 21:741-747.

13. Holten Lützhøft HC, Halling-Sørensen B, Jørgensen SE: Algal toxicity of antibacterial agents applied in Danish fish farming. Arch Environ Contam Toxicol 1999, 36:1-6.

14. Liu Y, Gao B, Yue Q, Guan Y, Wang Y, Huang L: Influences of two antibiotic contaminants on the production, release and toxicity of microcystins. Ecotoxicol Environ Saf 2012, 77:79-87.

15. Gonzalez-Pleiter M, Gonzalo S, Rodea-Palomares I, Leganes F, Rosal R, Boltes K, Marco E, Fernandez-Pinas F: Toxicity of five antibiotics and their mixtures towards photosynthetic aquatic organisms: implications for environmental risk assessment. Water Res 2013, 47:2050-2064.

16. Ball $P$ : The clinical development and launch of amoxicillin/clavulanate for the treatment of a range of community-acquired infections. Int J Antimicrob Agents 2007, 30(Suppl 2):S113-S117.

17. Li S-Z, Li X-Y, Wang D-Z: Membrane (RO-UF) filtration for antibiotic wastewater treatment and recovery of antibiotics. Sep Purif Technol 2004, 34:109-114.

18. Zhang J, Giorno L, Drioli E: Study of a hybrid process combining PACs and membrane operations for antibiotic wastewater treatment. Desalination 2006, 194:101-107.

19. Vergili I: Application of nanofiltration for the removal of carbamazepine diclofenac and ibuprofen from drinking water sources. J Environ Manage 2013, 127:177-187.

20. Sharma S, Ruparelia JP, Patel ML: A general review on Advanced Oxidation Processes for waste water treatment. In Nirma University International Conference, Ahmedabad, Gujarat. 2011

21. Surampalli RY, Adams CD, Champagne P, Ong SK, Tyagi RD, Zhang TC Bhandari A: Contaminants of Emerging Environmental Concern. Reston, Virginia: American Society of Civil Engineers; 2009:483.

22. Radjenovic J, Petrovic M, Ventura F, Barcelo D: Rejection of pharmaceuticals in nanofiltration and reverse osmosis membrane drinking water treatment. Water Res 2008, 42:3601-3610.

23. Gholami M, Mirzaei R, Rezaei Kalantary R, Sabzali A, Gatei F: Performance evaluation of reverse osmosis technology for selected antibiotics removal from synthetic pharmaceutical wastewater. J Environ Health Sci Eng 2012, 9:1-19.

24. Zhang W, He G, Gao P, Chen G: Development and characterization of composite nanofiltration membranes and their application in concentration of antibiotics. Sep Purif Technol 2003, 30:27-35.

25. Wang KY, Chung T-S: The characterization of flat composite nanofiltration membranes and their applications in the separation of Cephalexin. J Membr Sci 2005, 247:37-50.

26. Omidvar M, Mousavi SM, Soltanieh M, Safekordi AA: Preparation and characterization of poly (ethersulfone) nanofiltration membranes for amoxicillin removal from contaminated water. J Environ Health Sci Eng 2014, 12:1-18

27. Al-Abachi MQ, Haddi H, Al-Abachi AM: Spectrophotometric determination of amoxicillin by reaction with $\mathrm{N}, \mathrm{N}$-dimethyl-p-phenylenediamine and potassium hexacyanoferrate(III). Anal Chim Acta 2005, 55:184-189.

28. Baker RW: Membrane Technology and Applications. 2nd edition. Membrane Technology and Research, Inc., Menlo Park, California: John Wiley \& Sons; 2004.

29. Sharmiza A, Manh H, Huanting W, Zongli X: Commercial PTFE membranes for membrane distillation application: effect of microstructure and support material. Desalination 2012, 284:297-308.

30. Lin C-J, Rao P, Shirazi S: Effect of operating parameters on permeate flux decline caused by cake formation - a model study. Desalination 2005, 171:95-105.

31. Reddy AVR, Patel HR: Chemically treated polyethersulfone/polyacrylonitrile blend ultrafiltration membranes for better fouling resistance. Desalination 2008, 221:318-323.
32. Qiu Y, Rahman N, Matsuyama H: Preparation of hydrophilic poly(vinyl butyral)/ Pluronic F127 blend hollow fiber membrane via thermally induced phase separation. Sep Purif Technol 2008, 61:1-8.

33. Zazouli MA, Susanto $H$, Nasseri S, Ulbricht M: Influences of solution chemistry and polymeric natural organic matter on the removal of aquatic pharmaceutical residuals by nanofiltration. Water Res 2009, 43:3270-3280.

34. Salgın S, Salgın U, Soyer N: Streaming potential measurements of polyethersulfone ultrafiltration membranes to determine salt effects on membrane zeta potential. Int J Electrochem Sci 2013, 8:4073-4084.

35. Arkhangelsky E, Kuzmenko D, Gitis V: Impact of chemical cleaning on properties and functioning of polyethersulfone membranes. J Membr Sci 2007, 305:176-184

36. Derakhsheshpoor R, Homayoonfal M, Akbari A, Mehrnia MR: Amoxicillin separation from pharmaceutical wastewater by high permeability polysulfone nanofiltration membrane. J Environ Health Sci Eng 2013, 11:1-9.

doi:10.1186/s40201-014-0127-

Cite this article as: Moarefian et al:: Removal of amoxicillin from wastewater by self-made Polyethersulfone membrane using nanofiltration. Journal of Environmental Health Science \& Engineering 2014 12:127.

\section{Submit your next manuscript to BioMed Central and take full advantage of:}

- Convenient online submission

- Thorough peer review

- No space constraints or color figure charges

- Immediate publication on acceptance

- Inclusion in PubMed, CAS, Scopus and Google Scholar

- Research which is freely available for redistribution

Submit your manuscript at www.biomedcentral.com/submit
C Biomed Central 